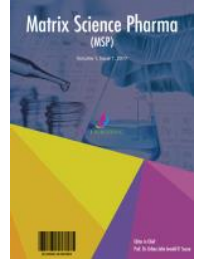

\title{
STATISTICAL ANALYSIS OF RISK FACTORS AFFECTING THE PROGNOSIS OF BILIARY ATRESIA IN INFANTS
} \author{
Rana Rehan Khalid ${ }^{1}$, Abdul Rauf Siddiqi ${ }^{1}$, * \\ ${ }^{1}$ Department of Biosciences, COMSATS Institute of Information Technology (CIIT), Islamabad-45550, Pakistan \\ ${ }^{2}$ Allama Iqbal Medical College Lahore, Pakistan \\ ${ }^{3}$ Fatima Jinnah Medical University, Lahore, Pakistan \\ ${ }^{4}$ College of Informatics, Huazhong Agricultural University (HZAU), Wuhan, P.R. China \\ ${ }^{5}$ Pakistan Institute of Nuclear Medicine (PINUM), Faisalabad, Pakistan \\ ${ }^{6}$ Institute of Pharmacy, Physiology and Pharmacology, University of Agriculture Faisalabad, Faisalabad, Pakistan \\ *Correspondence Author email: abdulraufsher@gmail.com
}

Arooma Maryam ${ }^{1}$, Sadia Aslam², Sidra Saif ${ }^{3}$, Tehzeeb Aslam ${ }^{3}$, Kishver Tusleem³, Muhammad Tahir ul Qamar ${ }^{4}$, Imran Abdullah ${ }^{5}$, Atifa Mushtaq ${ }^{6}$

This is an open access article distributed under the Creative Commons Attribution License, which permits unrestricted use, distribution, and reproduction in any medium, provided the original work is properly cited.

\section{ARTICLE DETAILS}

Article History:

Received 12 May2017

Accepted 12 July 2017

Available online 21 September 2017

Keywords:

Biliary Atresia, Blood group incompatibility, maternal infection

\section{ABSTRACT}

Biliary atresia often neglected as normal transition neonatal jaundice reports high incidence in Pakistan in contras to worldwide statistics. In contrast to data reported worldwide high mortality and morbidity rate of Biliary Atresia was reported within the Faisalabad region of Pakistan which indicates poor disease management. To understand the exact etiology of this disease, present study undertook a research initiative to define unique causes and clinical risk factors associated to Biliary atresia which help in early diagnosis. We intended to find strongly associated risk factors which distinguish it from early onset normal transition jaundice and suggest good prognostic measures for disease management. Logistic Regression and Pearson chi square test reports high incidence rate of Biliary atresia in newly born baby boys (64\%) than in female peers. Only $27 \%$ of survival rate of this disease was recorded. Unique association of disease with mother child blood group incompatibility $(\mathrm{P}<0.05)$ and other simultaneous neonatal infection $(\mathrm{P}$ $<0.05)$ shown to contribute significantly to high neonatal death toll $(72.8 \%)$. Moreover, mother health status $(\mathrm{P}<0.05)$ and maternal infection like diabetes and/or hypothyroidism $(\mathrm{P}<0.05)$ during gestation period are also significant contributing factors to outcome of Biliary atresia. Based on findings we suggest careful examination of neonates if any of the reported risk factors is observed in first 3 days of birth to manage Biliary Atresia. Study also emphasizes on the importance of maternal health care and proper disease management of maternal infections that otherwise predispose neonates at risk of health disorder.

\section{INTRODUCTION}

Unlike the data reported worldwide, biliary atresia is not amongst rare disorders in Pakistan population. Within the Faisalabad region with adjoining 48 different cities 300 cases were reported within a year which indicates high incidence rate of this devastation disease. As exact etiology of neonatal biliary atresia is unknown because of which poor prognosis ultimate leads to loss of life $[1,2]$. Neonatal jaundice is a common problem that designates to all situation in the infants in which the serum bilirubin is elevated to cause, both, minimally visible yellowing of the skin and ocular sclera. It affects 60 percent of full-term infants and 80 percent of preterm infants in the first three days after birth. Normally it is categorized as physiological jaundice and pathological jaundice. Most prevalent of them is physiological neonatal jaundice [3]. Of several reported reasons, most frequently known are increased enterohepatic circulation of bilirubin with least hepatic uptake of bilirubin from plasma and defective bilirubin conjugation. Understanding of hepatic and extrahepatic mechanism of bilirubin metabolism responsible for physiological jaundice of newborn is essential and would be helpful for diagnostic and therapeutic decisions [4]. Features that characterize pathological jaundice from physiological jaundice is that pathological group occurs within the first 24 hours of birth. The baby may be unwell on examination; have an enlarged liver or spleen; have a rash; have pale stools or be pale. Bilirubin level can be very high, $>275 \mathrm{~mol} / \mathrm{l}$ in hemolytic disease. Jaundice lasting more than two weeks is prolonged jaundice and requires careful clinical investigations [5]. Prolonged jaundice is clearly indicative of Biliary atresia (BA). It is a hepatobiliary disorder occurs due to destruction of both intrahepatic and extrahepatic bile ducts which initiates the inflammation process in liver. It is considered as a rare disorder in neonates which is thought to effect one out of 10,000 live births. It most likely to effect female patients and mostly reported in Asian population. This life-threatening disease if left untreated can lead to progressive liver cirrhosis which ends at death of child within 2 years. As hyperbilirubinemia is common medical condition in infants so it become difficult initially for some period until and unless become more pronounced [6]

In biliary atresia gender biasness, has been reported in various studies and newly born baby girls are among the remarkably affected members of this diseases. Maternal health status is directly related to child birth weight. ABO incompatibility between maternal and child blood group cause massive hemolysis in the fetus. If the baby survived to be delivered, it would often be severely anemic, grossly jaundiced, and critically ill, with frequent neurological consequence $[7,8]$. If mother is suffering from over activity of thyroid hormones, or from cell mediated immune destruction of thyroid glands during pregnancy, it will directly affect the child growth. Specifically, if mother is suffering from hypothyroidism during the third trimester of pregnancy it would badly effect birth weight of child. Risk of neonatal jaundice will also be high if a mother is suffering from diabetes during its pregnancy. Maternal health and maternal age are also one of the contributing factors for jaundice in neonate [9]. In infant-mother dyads increased risk of developing jaundice seems greatly associated with maternal factors but no clear association has been established with BA till now [10]. Misconception of normal transition of unconjugated bilirubin level in infants greatly effects prognosis of BA. In healthy infants, it normally takes few days to eliminate but if prolonged more than two weeks or appears after two weeks of birth may indicate presence of BA [11]. Early-onset infection i.e. fever, bacterial infections predispose majority of neonates to prolonged jaundice [7]. Complication in diagnosis 
of biliary atresia has increases the incidence of this deadly disease among neonates of South East Asian population [2].

In contrast to research reported worldwide about the risk factors of Biliary Atresia worldwide no such study has been reported so far in Pakistani population. Looking at high incidence and maximum number of reported cases current study was design to investigate the role of risk factors to diseases occurrence in neonates. To develop a convincible association of disease symptoms in infants to biliary atresia and distinguish its clinical presentation from commonly occurring physiological jaundice in Pakistani population we collected multifactorial data of neonates who had their HIDA scan and treatments from PINUM hospital Faisalabad. This study aimed at dealing with the clinical challenge of distinguishing neonates with susceptibility of biliary atresia based on clinical presentation data. Implication of neonatal health relevant factor (birth weight, gender, $\mathrm{ABO}$ incompatibility, other neonatal infection, age at disease presentation, age at diagnosis and time to recover after diagnosis) and maternal factors (maternal health, maternal infections, maternal age) on neonatal mortality and morbidity of was evaluated in terms of biliary atresia. Additionally, study also focuses on assessment of awareness of BA among attendants of neonates by peeking into difference between the age at disease presentation and age of diagnosis.

\section{MATERIALS AND METHODS}

\subsection{Patients}

Cross sectional comparative study was conducted on 184 neonates during one-year period and prospectively identified neonates of few days to one year who had their Hepatobiliary scintigraphy from Pakistan Institute of Nuclear Medicine (PINUM). We categorized the patient's data into two groups, one in which biliary atresia was ruled out after treatment and subsequent HIDA scan and while the other is biliary atresia not ruled out group in which disease tends to persist.

\subsection{Inclusion Exclusion Criteria}

Based on all questions positively answered, we selected 184 patients from 300 files which were later categorized in to two groups. Out of our selected patients 90 cases belongs to biliary atresia's ruled out group and 94 were from biliary atresia not ruled out group. In addition to this, neonate who got diagnosed of biliary atresia within 28 days of birth were included in the study.

\subsection{Attendants Consent}

The aim of the study was explained to the attendants of the neonates. Interviews were scheduled for those who were willing to participate in the study and gave their written consent.

\subsection{Data Collection}

All cases were subjected to the following; careful history was recorded related to factors that might lead to prolonged jaundice. Factors including maternal infection i.e. hyperthyroidism, diabetes, age at presentation of disease, age when first diagnosed, duration of jaundice to assess time of recovery, maternal $\mathrm{ABO}$ for detection of in-compatibility, maternal age and health status during child birth, child gender, birthweight and presence any other neonatal infection during the time when he/she is suffering from biliary atresia. From hospital record files and interviews of minor's attendants we gathered information against factors given in Table 1. To assess the age of presentation of disease, date of birth and date of HIDA Scan report were further matched. We collected data related to age at presentation of disease in neonates and time when first diagnosed of Biliary atresia to assess the awareness among people about this disease. Along with this, status of child whether alive or dead was recorded to measure the survival rate from this disease within the Faisalabad region.

Once data collection was completed we performed statistical analysis in SPSS version 13.0. For statistical analysis, all the parameters were further categorized into groups shown in Table 1 . Frequency distribution of the selected cases was calculated and shown graphically.

Table 1: Neonatal and Maternal Health Related Factors Understudy for Biliary Atresia Disease Analysis.

\begin{tabular}{|c|c|c|c|c|}
\hline \multicolumn{5}{|c|}{ Factors Associated to Neonate Health } \\
\hline Factors & & Categorie & & \\
\hline Gender & \multicolumn{2}{|l|}{ Male } & \multicolumn{2}{|c|}{ Female } \\
\hline ABO Incompatibility & \multicolumn{2}{|l|}{ Yes } & \multicolumn{2}{|l|}{ No } \\
\hline Neonatal Infection & \multicolumn{2}{|l|}{ Yes } & \multicolumn{2}{|l|}{ No } \\
\hline Birth weight $(\mathrm{kg})$ & $<=2.5$ & $2.6-2.7$ & \multicolumn{2}{|c|}{$2.8+$} \\
\hline Age at Disease Presentation (days) & $<=30$ & $31-60$ & $61-90$ & $91+$ \\
\hline Age When First Diagnosed (days) & $<=3$ & 4-7 & $8-14$ days & $15+$ \\
\hline Time to Recover (days) & $<=60$ & $61-120$ & $121-180$ & $181+$ \\
\hline Status & \multicolumn{2}{|l|}{ Alive } & \multicolumn{2}{|c|}{ Death } \\
\hline \multicolumn{5}{|c|}{ Factors Associated to Mother's Health } \\
\hline Maternal_age (years) & $<=24$ & $25-30$ & $31-36$ & $37+$ \\
\hline Maternal Infection & Hyperthyroidism & Diabetic & None & \\
\hline Maternal health & Obese & Weak & Normal & \\
\hline
\end{tabular}

\subsection{Pearson Chi Square Test}

Relationships of all the factors with the two groups of neonatal jaundice were calculated through Pearson chi square test [12]. We separately applied Pearson chi square test to assess whether maternal health associated factors contribute to the outcome of Biliary Atresia in neonates or not.

\subsection{Binomial Logistic Regression}

Moreover, binomial logistic regression was applied on all factors previously studied through Pearson chi square test, to evaluate the most significant factor contributing to mortality and morbidity in neonates due to Biliary Atresia [13]. For logistic regression, we took neonates status i.e. Alive or death as dependent variable and encoded them with values 0 and 1 respectively. To evaluate the direct association of following characteristics i.e. Age at disease presentation, Birth weight, time when first diagnosed, Maternal age, Gender, ABO Incompatibility, Neonatal infection, maternal infection and maternal health we took them as categorical and independent variables in the first step, encoded them applied them in equation stepwise. With each step progression, most nonsignificant variable with has high significance value was removed.

\subsection{Descriptive Statistics for Age at Disease Presentation and Recovery Time}

To calculate mean age of the disease presentation in neonates and how much average time they take to recover after disease diagnosis descriptive statistics were applied at $95 \%$ confidence interval.

\section{RESULTS}

To anticipate the likelihood of BA and to establish convincible association of neonatal health associated and maternal factors to early diagnosis of biliary atresia statistical study was carried out. Maternal infections, maternal health status and other neonatal infections strongly correlate with the early onset of biliary atresia in neonates. Percentage and frequency distribution of 184 cases in terms of neonate's gender, birth weight, $\mathrm{ABO}$ incompatibility, infections other than prolonged jaundice and status of child whether dead or alive is given in Figure 1.

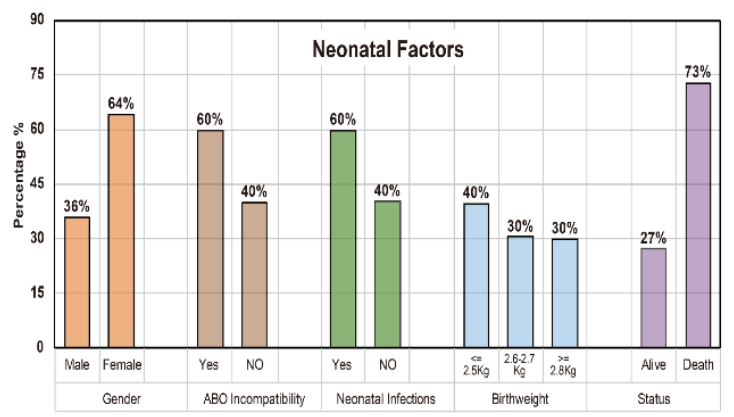


Figure 1: Graphical illustration of percentage distribution of neonatal health associated risk factors i.e. Gender, ABO Incompatibility, Neonatal infection, Birth weight and child status based on clinical data of 184 Biliary Atresia patients.

Out of 184 cases $36 \%$ cases were reported in baby girls while $64 \%$ cases were observed in baby boys. Huge percentage difference of males (64\%) and females $(35.9 \%)$ showed the gender biasness/male disadvantage theory but Pearson chi square test results doesn't conform to this theory. Although a study reports high incidence of biliary atresia in females and associate the delay of cognitive skills in females to their high bilirubin level due to biliary atresia but in our data male peers were found more vulnerable to this disease $[5,14]$. For variable birthweight; $38 \%$ neonates were less than or equals to $2.5 \mathrm{~kg}$, $36 \%$ neonates weigh between $2.6-2.7$ $\mathrm{kg}$ while $32 \%$ cases were reported to have more than $2.8 \mathrm{~kg}$ weight at the time of birth. In case of blood group incompatibility, $57 \%$ neonatal blood group was found incompatible with the maternal blood group while rest of the case $(43 \%)$ were having same blood group as of mother. Various studies reported that low birth weight as a risk factor in case of early neonatal jaundice but in BA data it showed non-significant association to both the groups $[3,7]$. In neonates, low birthweight might be a contributing factor for early onset of hyperbiliruenemia but it doesn't significantly affect to disease burden in case of biliary atresia. Work by Madan and coworkers reported 31\% incidence of $\mathrm{ABO}$ incompatibility in terms of prolonged jaundice in neonates which strong confirms results of our study $[8,14,15]$. Remarkable ratio and strong association of mother child blood group incompatibility has been reported in our analyzed data. A study demonstrated that, in $\mathrm{ABO}$ incompatible neonates especially neonates of A blood group born to 0 positive mother becomes more incompatible and hemolyzed. Highly morbidity and mortality rate reported in our data suggest early transfusion of ABO-specific red blood cells in neonates of less than 4 months to deal with incompatibility [16-18]. About $55 \%$ of the subjects have been reported to be simultaneously suffering from other disease infections during the progression of biliary atresia while $45 \%$ neonates only had the problem of prolonged jaundice during that tenure. Respondent's interviews revealed that out of our selected cases $73 \%$ neonates could not survive once diagnosed for biliary atresia not ruled status after HIDA scan shown in Figure 1. Likewise, we represented the percentage distribution of maternal health associated parameters graphically which shows that in $23 \%$ of the neonates, their mothers were diabetic during pregnancy, $10 \%$ neonatal mothers were suffering from hypothyroidism while in $67 \%$ cases mothers remained healthy given in Figure 2(A). In maternal health variable $41 \%$ such cases were reported in which mother was physically weak during pregnancy as they were underweight, in $17 \%$ neonates' maternal obesity was while in $42 \%$ cases mothers were found physically healthy shown in Figure 2.

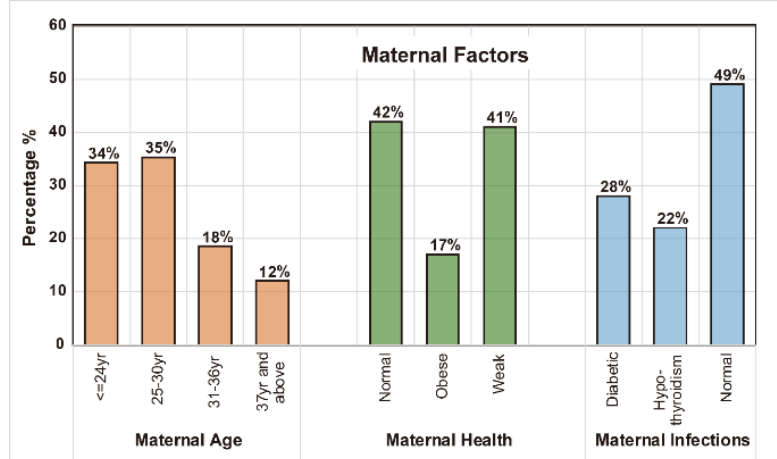

Figure 2: Graphical illustration of percentage distribution of maternal health associated risk factors i.e. maternal age, maternal health and maternal infections based on clinical data of 184 Biliary Atresia patients. To have an estimate of the awareness about biliary atresia amongst community we recorded three parameters i.e. age at disease presentation, age at diagnosis and time of recovery after diagnosis. Frequency distributions in Figure 3 (A) shows that symptoms of jaundice appear in $64 \%$ of neonates within 3 days of birth while $3 \%$ and $6 \%$ neonates showed symptoms in 4-7 days and 8-14 days respectively. In about $26 \%$ patients, obvious symptoms of this disease appeared in more than 15 days. In more than $28.2 \%$ disease symptoms appeared in 30 days, $21.7 \%$ showed in 31 60 days, $21.1 \%$ in $61-90$ days and $28.8 \%$ in more than 90 days. Of the total $27 \%$ alive cases $38 \%$ neonates recovered within 60 days, $26 \%$ neonates recovered in 61-120 days' time, while $14 \%$, and $2 \%$ neonates took longer time of 121-180 days and more than 180 days respectively for recovery from biliary atresia. In both the groups majority cases were diagnosed in less than 3 weeks' time which shows a healthy trend about neonatal health awareness in Pakistani population.
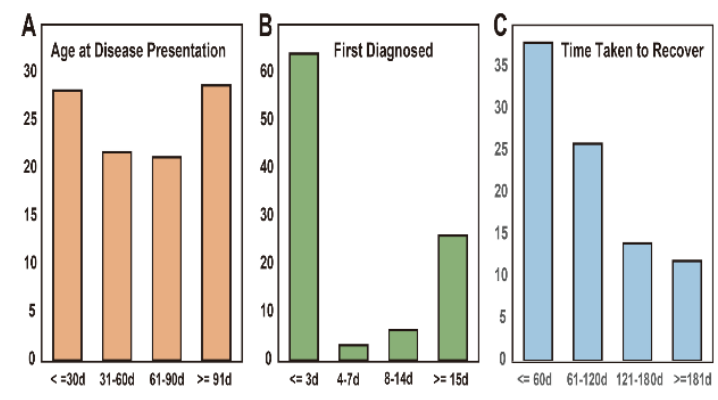

Figure 3: illustrating bar graphs based on percentage distribution of age at presentation of disease (A), Age at diagnosis (B) and age at recovery (C) calculated from data of 184 neonates suffered from Biliary Atresia.

While huge difference of mean age of diagnosis and time of recovery in Table 5 and Table 6 upsurge the need for better prognosis and efficient communication between the pediatrician and care takers could lead to early recovery from this disease. Recently a study reported significant difference in the median age of the biliary atresia presentation and its time of recovery while in our data same effect has been observed in both the parameters (age at disease presentation and age at recovery) [19].

To find out the association/ significance of all those factor that are related to neonatal health with the both the groups of prolonged jaundice; biliary atresia ruled out and biliary atresia not ruled out group, we applied Pearson chi square test. Results given in Table 2 indicate that ABO incompatibility between neonate and maternal blood and other immediate infections after jaundice in neonates were major contributing factors to disease severity as their $P$ values are less than 0.05 significance level defined during Pearson chi square test application. While of three of maternal factors under study, maternal infection and maternal health during pregnancy are strongly associated with the neonatal jaundice which may prolong due to biliary atresia (Table 3 ).

Table 2: Percentage Distribution of Neonates Health Associated Risk Factors Between Both Groups of Biliary Atresia and Their Association Analysis with Disease Through Pearson Chi Square Test.

\begin{tabular}{|c|c|c|c|c|}
\hline $\begin{array}{l}\text { Risk } \\
\text { factors }\end{array}$ & $\begin{array}{l}\text { Ruled out \% within } \\
\text { the group }(n=90)\end{array}$ & $\begin{array}{l}\text { Not ruled out \% within } \\
\text { the group }(n=94)\end{array}$ & $\begin{array}{l}\text { Chi-Square } \\
\text { value }\end{array}$ & P value \\
\hline \multicolumn{5}{|c|}{ Birth weight(kg) } \\
\hline$<=2.5$ & $37.8(34)$ & 41.5(39) & \multirow{3}{*}{2.747} & \multirow{3}{*}{0.253} \\
\hline $2.6-2.7$ & $28.9(26)$ & $31.9(30)$ & & \\
\hline $2.8+$ & $33.3(30)$ & $26.6(25)$ & & \\
\hline \multicolumn{5}{|c|}{ Neonatal Infection } \\
\hline Yes & $54.4(49)$ & $77.65(73)$ & \multirow[t]{2}{*}{11.09} & \multirow[t]{2}{*}{$0.0008^{*}$} \\
\hline No & $45.6(41)$ & $22.34(21)$ & & \\
\hline \multicolumn{5}{|c|}{ ABO Incompatibilit } \\
\hline Yes & $50.0(45)$ & $69.15(65)$ & \multirow[t]{2}{*}{7.0122} & \multirow[t]{2}{*}{$0.0081^{*}$} \\
\hline No & $50.0(45)$ & $30.85(29)$ & & \\
\hline \multicolumn{5}{|c|}{ Age at presentation } \\
\hline$<=30$ & $34.4(31)$ & $22.3(21)$ & \multirow{4}{*}{6.415} & \multirow{4}{*}{0.093} \\
\hline $31-60$ & 21.1(19) & $22.3(21)$ & & \\
\hline $61-90$ & $23.3(21)$ & 19.1(18) & & \\
\hline $91+$ & 21.1(19) & $36.2(34)$ & & \\
\hline \multicolumn{5}{|c|}{ First diagnosed (days) } \\
\hline$<=3$ & $65.6(59)$ & $62.8(59)$ & \multirow{4}{*}{2.664} & \multirow{4}{*}{0.446} \\
\hline $4-7$ & $2.2(2)$ & $4.3(4)$ & & \\
\hline $8-14$ & $8.9(8)$ & $4.3(4)$ & & \\
\hline $15+$ & $23.3(21)$ & $28.7(27)$ & & \\
\hline \multicolumn{5}{|l|}{ Gender } \\
\hline Female & 41.1(37) & $30.9(29)$ & 2.104 & 0.147 \\
\hline
\end{tabular}




\begin{tabular}{|c|c|c|c|c|}
\hline Male & $58.9(53)$ & $69.1(65)$ & & \\
\hline \multicolumn{5}{|c|}{ Time recover(days) } \\
\hline$<=60$ & $36.8(14)$ & $41.7(5)$ & \multirow{4}{*}{0.489} & \multirow{4}{*}{0.921} \\
\hline $61-120$ & $26.3(10)$ & $25.0(3)$ & & \\
\hline $121-180$ & $15.8(6)$ & $8.3(1)$ & & \\
\hline $181+$ & $21.1(3)$ & $25.0(3)$ & & \\
\hline
\end{tabular}

*Show significant association with $P$ values $<0.05$ (5\% level of significance) highlighted in bold

Table 3: Percentage Distribution of Maternal Health Related Risk Factors Between Both Groups of Biliary Atresia and Their Association Analysis with Disease Through Pearson Chi Square Test

\begin{tabular}{|c|c|c|c|c|}
\hline $\begin{array}{l}\text { Maternal } \\
\text { Causes/risk } \\
\text { factors }\end{array}$ & $\begin{array}{l}\text { Ruled out } \% \\
\text { within the group } \\
(\mathrm{n}=90)\end{array}$ & $\begin{array}{l}\text { Not ruled out } \% \\
\text { within the group } \\
(n=94)\end{array}$ & $\begin{array}{l}\text { Chi- } \\
\text { Square } \\
\text { value }\end{array}$ & P value \\
\hline \multicolumn{5}{|c|}{ Maternal age(years) } \\
\hline$<=24$ & $33.3(30)$ & $35.1(33)$ & \multirow[t]{4}{*}{4.947} & \multirow[t]{4}{*}{0.176} \\
\hline $25-30$ & $30.0(27)$ & $40.4(38)$ & & \\
\hline $31-36$ & $20.0(18)$ & $17.0(16)$ & & \\
\hline $37+$ & $16.7(15)$ & $7.4(7)$ & & \\
\hline \multicolumn{5}{|c|}{ Maternal Health } \\
\hline Normal & $28.9(26)$ & $54.3(51)$ & \multirow[t]{3}{*}{15.907} & \multirow[t]{3}{*}{$0.0001^{*}$} \\
\hline Obese & $15.6(14)$ & $18.1(17)$ & & \\
\hline Weak & $55.6(50)$ & $27.7(26)$ & & \\
\hline \multicolumn{5}{|c|}{ Maternal Infection } \\
\hline Diabetic & $27.78(25)$ & $28.72(27)$ & \multirow[t]{3}{*}{7.3384} & \multirow[t]{3}{*}{$0.0255^{*}$} \\
\hline $\begin{array}{l}\text { Hypo- } \\
\text { thyroidism }\end{array}$ & $14.44(13)$ & $29.79(28)$ & & \\
\hline Normal & $57.78(52)$ & $41.49(39)$ & & \\
\hline
\end{tabular}

\section{* Show significant association with $P$ values $<0.05$ (5\% level of} significance)

Strong association of these four factors predispose newly borne babies to biliary atresia. Furthermore, logistic regression was applied to explore the most significant and causative factors affecting the outcome of neonatal jaundice. Significant statistical association of ABO incompatibility and simultaneous neonatal infection apart from jaundice with the high mortality rate is indicated by 0.000 and 0.004 significance value respectively in addition to 0.000 constant value in $7^{\text {th }}$ step of logistic regression shown in Table 4.

Table 4: logistic regression analysis of independent neonatal and maternal health related variables to study their effect on mortality (Alive/Death) rate of Biliary Atresia.

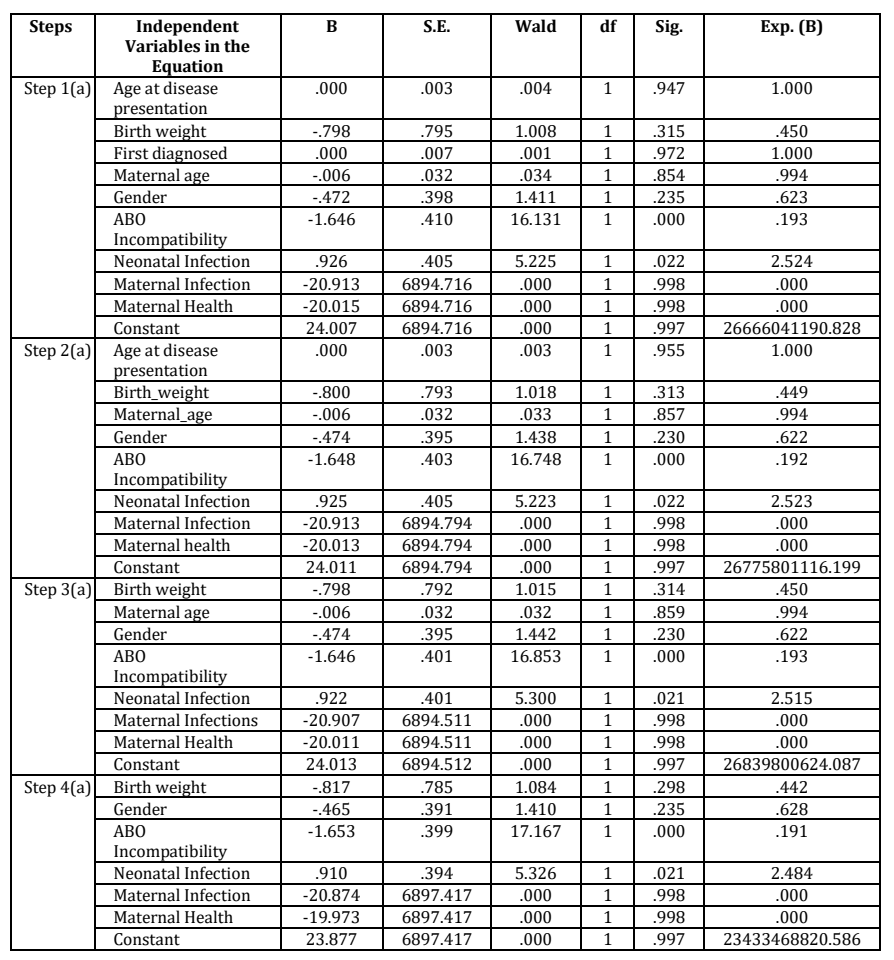

\begin{tabular}{|l|l|}
\hline Step 5(a) & Gender \\
\hline
\end{tabular}

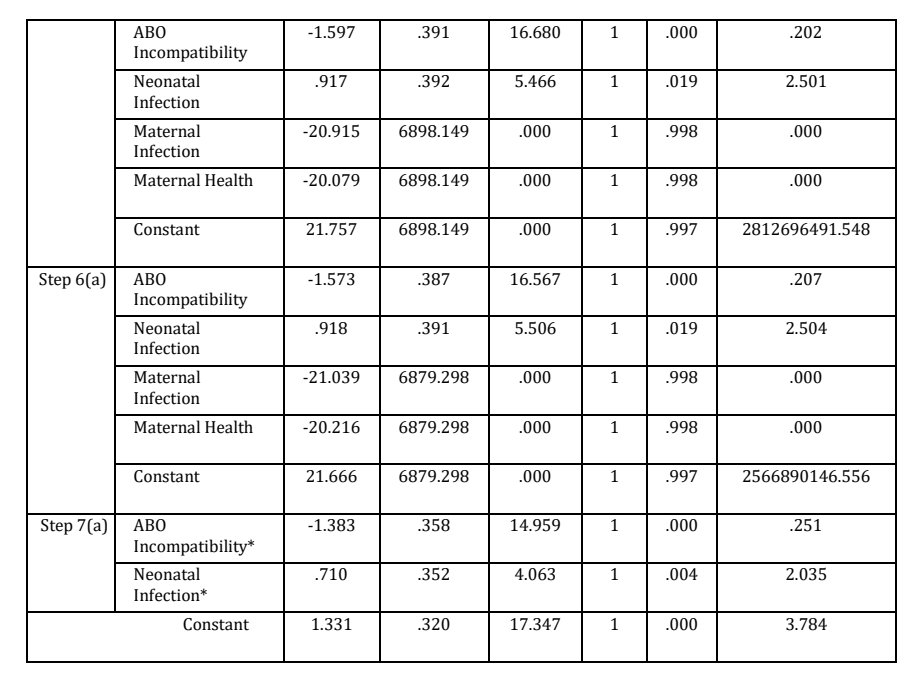

* means most significant factor with least $\mathrm{S}$ value (.000 and .004) and constant value 0.00 in last step

The study also focused to decipher the average age of biliary atresia occurrence in neonates and to assess how much time it takes to recover after diagnosis. For that matter descriptive statistical analysis of both these parameters revealed that in biliary atresia ruled out group; means time of disease occurrence is 17 days [95\%CI: 7.12-0.17.82] while mean time to recover is 131 days [94.56-167.49]. Likewise, in opposite group of patients in which biliary atresia has not been ruled out mean age of disease presentation was calculated to be 18.60 days [95\% CI: $10.43-26.76$ ] while mean recovery times was 138 days [95\%CI: 59.13-217.53] as shown in Table 5 and 6 . No significant difference in terms of both these parameters was observed between the two group.

Table 5: Descriptive Statistics applied for calculation of Mean Age of First Diagnosis After Neonatal Jaundice at 95\% Confidence Interval.

\begin{tabular}{|c|c|c|c|c|}
\hline \multirow{11}{*}{$\begin{array}{l}\text { First diagnosed } \\
\text { (days) }\end{array}$} & \multirow{6}{*}{$\begin{array}{l}\quad \text { Group } \\
\text { Not ruled } \\
\text { out }\end{array}$} & \multicolumn{3}{|c|}{ Statistics } \\
\hline & & Mean & \multicolumn{2}{|c|}{18.60} \\
\hline & & \multirow[t]{2}{*}{$\begin{array}{l}95 \% \text { Confidence Interval } \\
\text { for Mean }\end{array}$} & $\begin{array}{l}\text { Lower } \\
\text { Bound }\end{array}$ & 10.43 \\
\hline & & & $\begin{array}{l}\text { Upper } \\
\text { Bound }\end{array}$ & 26.76 \\
\hline & & 5\% Trimmed Mean & \multicolumn{2}{|c|}{11.82} \\
\hline & & Median & \multicolumn{2}{|c|}{1.00} \\
\hline & \multirow[t]{5}{*}{ Ruled out } & Mean & \multicolumn{2}{|c|}{12.47} \\
\hline & & $\begin{array}{l}95 \% \text { Confidence Interval } \\
\text { for Mean }\end{array}$ & $\begin{array}{l}\text { Lower } \\
\text { Bound } \\
\end{array}$ & 7.12 \\
\hline & & & $\begin{array}{l}\text { Upper } \\
\text { Bound }\end{array}$ & 17.82 \\
\hline & & 5\% Trimmed Mean & \multicolumn{2}{|c|}{7.93} \\
\hline & & Median & \multicolumn{2}{|c|}{2.00} \\
\hline
\end{tabular}

Table 6: Descriptive Statistics Applied for Calculating Mean Age at Recovery from Biliary Atresia at $95 \%$ Confidence Interval.

\begin{tabular}{|c|c|c|c|c|}
\hline Variable & Group & \multicolumn{3}{|c|}{ Statistics } \\
\hline \multirow{4}{*}{$\begin{array}{c}\text { Time_recovery } \\
\text { (days) }\end{array}$} & \multirow[t]{4}{*}{ Ruled out } & Mean & \multicolumn{2}{|c|}{131.03} \\
\hline & & \multirow[t]{2}{*}{$\begin{array}{l}95 \% \text { Confidence Interval } \\
\text { for Mean }\end{array}$} & $\begin{array}{l}\text { Lower } \\
\text { bound }\end{array}$ & 94.56 \\
\hline & & & $\begin{array}{l}\text { Upper } \\
\text { bound }\end{array}$ & 167.49 \\
\hline & & Median & & \\
\hline \multirow{4}{*}{$\begin{array}{c}\text { Time_recovery } \\
\text { (days) }\end{array}$} & \multirow{4}{*}{$\begin{array}{c}\text { Not Ruled } \\
\text { out }\end{array}$} & Mean & \multicolumn{2}{|c|}{138.33} \\
\hline & & \multirow[t]{2}{*}{$\begin{array}{l}95 \% \text { Confidence Interval } \\
\text { for Mean }\end{array}$} & $\begin{array}{l}\text { Lower } \\
\text { bound }\end{array}$ & 59.13 \\
\hline & & & $\begin{array}{l}\text { Upper } \\
\text { bound }\end{array}$ & 217.53 \\
\hline & & Median & \multicolumn{2}{|c|}{105.00} \\
\hline
\end{tabular}

\section{DISCUSSION}

While high death rate may be a sign of poor prognosis or disease management. It may also depend on the severity of the symptoms and more likely on the socio-economic setup of the Faisalabad region. These findings emphasize on to the importance of an early detection of BA in neonates for timely management of disease.

\section{CONCLUSION}

Cite the article: Arooma Maryam, Sadia Aslam, Sidra Saif, Tehzeeb Aslam, Kishver Tusleem, Muhammad Tahir ul Qamar, Imran Abdulla h, Atifa Mushtaq, Rana Rehan Khalid, Abdul Rauf Siddiqi, (2017).Statistical Analysis Of Risk Factors Affecting The Prognosis Of Biliary Atresia In Infants. Matrix Science Pharma, $1(2): 20-24$. 
In summary, biliary atresia is defined based on available clinical data of infant which was maintained during the time of morbidity follow-up appointments till recovery. Case history including maternal health related information of all the neonates who were referred based on severity of neonatal jaundice for HIDA scan were recorded. Statistical analysis elucidated the most important recognizable factors among several commonly occurring risk features which may leads to misconception of normal transition jaundice in neonates and cause delay in diagnosis of biliary atresia. Therefore, study may prove helpful in identifying infants that are suffering from neonatal jaundice and are more prone to biliary atresia just from the glimpse of clinical data recorder initially. All these measures may improve early and accurate detection of BA in neonates for timely management of disease.

\section{REFERENCES}

[1] Chardot, C. 2006. Biliary atresia. Orphanet journal of rare diseases. 1, 28.

[2] Ho, N.K. 1992. Neonatal jaundice in Asia. Baillière's clinical haematology, 5, 131-142.

[3] Scrafford, C.G., Mullany, L.C., Katz, J., Khatry, S.K., LeClerq, S.C., Darmstadt, G.L., Tielsch, J.M. 2013. Incidence of and risk factors for neonatal jaundice among newborns in southern Nepal. Tropical Medicine \& International Health, 18, 1317-1328.

[4] Chen, H.T., Jeng, M.J., Soong, W.J., Yang, C.F., Tsao, P.C., Lee, Y.S., Chen, S.J., Tang, R.B. 2011. Hyperbilirubinemia with urinary tract infection in infants younger than eight weeks old. Journal of the Chinese Medical Association, 74, 159-163.

[5] Caudle, S.E., Katzenstein, J.M., Karpen, S., McLin, V. 2012. Developmental assessment of infants with biliary atresia: differences between boys and girls. Journal of pediatric gastroenterology and nutrition, 55, 384-389.

[6] Kelly, D.A., Davenport, M. 2007. Current management of biliary atresia. Archives of disease in childhood, 92, 1132-1135.

[7] Karakoyun, M., Baran, M., Turan, C., Kılıç, M., Ergun, O., Aydoğdu, S. 2017. Infants with extrahepatic biliary atresia: Effect of follow-up on the

[8] survival rate at Ege University Medical School transplantation center. Turk J Gastroenterol, 28, 298-302.
[9] Madan, N., Sood, S. 1987. Role of G6PD, ABO incompatibility, low birth weight and infection in neonatal hyperbilirubinaemia. Tropical and geographical medicine, 39, 163-168.

[10] Kuroda, T., Saeki, M., Morikawa, N., Fuchimoto, Y. 2005. Biliary atresia and pregnancy: puberty may be an important point for predicting the outcome. Journal of pediatric surgery, 40, 1852-1855.

[11] Stevenson, D.K., Dennery, P.A., Hintz, S.R. 2001. Understanding newborn jaundice, Journal of Perinatology, 21, S21.

[12] McKenzie, J., Zakarija, M. 1992. Fetal and neonatal hyperthyroidism and hypothyroidism due to maternal TSH receptor antibodies. Thyroid, 2, 155-159.

[13] Cochran, W.G. 1945. Some methods for strengthening the common $\chi 2$ tests. Biometrics, 10, 417-451

[14] Anderson, J., Philips, P. 1981. Regression, discrimination and measurement models for ordered categorical variables. Applied statistics, 22-31

[15] Chan, G.J., Lee, A.C., Baqui, A.H., Tan, J., Black, R.E. 2015. Prevalence of early-onset neonatal infection among newborns of mothers with bacterial infection or colonization: a systematic review and meta-analysis. BMC infectious diseases, 15, 118.

[16] Irshad, M., Muhammad, A., Hussain, M., Khan, B., Ali, N., Ahmad, A., Hayat, M., Karim, R. 2011. Prevalence of Rhesus type and ABO incompatibility in jaundiced neonates. Journal of Postgraduate Medical Institute (Peshawar-Pakistan), 25.

[17] McKiernan, P.J., Baker, A.J., Kelly, D.A. 2000. The frequency and outcome of biliary atresia in the UK and Ireland, The Lancet, 355, 25-29

[18] Watchko, J.F. 2009. Identification of neonates at risk for hazardous hyperbilirubinemia: emerging clinical insights. Pediatric clinics of North America, 56, 671-687.

[19] Jain, A., Poddar, U., Elhence, P., Tripathi, A., Shava, U., Yachha, S.K. 2014. Cholestasis in a neonate with $\mathrm{ABO}$ haemolytic disease of newborn following transfusion of $\mathrm{ABO}$ group-specific red cells compatible with neonatal serum: inspissated bile syndrome, Blood Transfusion, 12: 621.

[20] Dennery, P.A. 2002. Pharmacological interventions for the treatment of neonatal jaundice. in: Seminars in neonatology, 7,111-119. 